Barbara Antonioli, Massimo Filippini

The use of a variable cost function in the regulation of the Italian water industry

\author{
Quaderno N. 02-01
}

Decanato della Facoltà di Scienze economiche

Via Ospedale, 13 CH-6900 Lugano. Tel. 09191246 09 / 08. Fax 0919124629 


\title{
The use of a variable cost function in the regulation of the Italian water industry*
}

\author{
Barbara ANTONIOLI \\ University of Lugano \\ Department of Economics \\ Via Ospedale 13 \\ 6900 Lugano, Switzerland \\ and \\ University of Ferrara, Italy \\ Massimo FILIPPIN I \\ University of Lugano \\ Department of Economics \\ Via Ospedale 13 \\ 6900 Lugano, Switzerland \\ and
}

Swiss Federal Institute of Technology Zürich

\begin{abstract}
The purpose of this study is to estimate a multivariate variable cost function in order to analyze the cost structure of a sample of Italian water distribution companies.

The empirical results of this study could be used by the Italian Regulation Authority of this sector for two purposes: first, to improve the actual tariff regulation process, based on a benchmarking of variable costs, and second, to define the optimal size of a service territory in this sector.

A variable cost function was estimated using panel data for a sample of 32 water distribution firms operating at the provincial level over the period 19911995. Results indicate the importance of explanatory variables such as price of labor, water loss and service area characteristics.
\end{abstract}

\footnotetext{
* We are grateful to CISPEL and NOMISMA for general assistance in constructing the database for the empirical analysis. We would also like to thank Gina Poncini for proofreading the final version of this paper. The views expressed in this paper are strictly personal. Responsibility for any remaining errors lies solely with the authors.
} 
Results also indicate the existence of economies of output and customer density and the presence of small diseconomies of scale.

\section{Introduction}

In most countries, water distribution companies have a monopoly franchise to deliver water within their service territories, and for this reason a rate regulation by a regulatory commission is necessary.

This raises the problem of determining proper rates for the delivery of water. On the one hand, prices should be high enough to guarantee the viability of the regulated firm; on the other hand, prices that are set too high cause welfare losses. Because of asymmetric information, the regulator does not know the firm's true costs. High costs may be due to the firm's particular production situation or just because of its inefficiency.

In Italy, as in other European countries, a regulatory reform was introduced in the water industry in 1994 in order to give the water companies better incentives for efficient production and pricing ${ }^{1}$. In particular, with the introduction of a new law for the water industry, the Italian government wanted to implement a new method to regulate tariffs based on an incentive regulation approach ${ }^{2}$.

The regulation method adopted by the Italian Regulation Authority is based on the yardstick regulation approach proposed by Shleifer (1985). In practice, the tariffs adopted by the water distribution companies have to be approved by the regulation authority, which make a decision on the basis of a benchmarking analysis of the variable costs of the companies. ${ }^{3}$ This benchmarking analysis is performed using the estimation results of a variable cost function estimated using a data set for only one year for a sample of Italian water distribution companies.

\footnotetext{
1 See Law n. 36/94.

2 See Laffont and Tirole, 1993.

3 The typical tariff used by the Italian water distribution companies is a two-part tariff, with a fixed and a variable component. The benchmarking analysis is performed only on the variable part of the tariff.
} 
The purpose of this paper is to make a contribution to the regulation process by estimating a multivariate variable cost function using panel data for a sample of Italian water distribution companies. Therefore, in the empirical part of the paper, we specify a variable cost function, which incorporates as explanatory variables some service area characteristics that are not taken into account in the model used by the regulation authority.

This article is organized as follows. In the next section we present the regulation of the Italian water distribution sector. In section 3 a variable cost function for water distribution companies is suggested. In the fourth section the database for the estimation is presented. The estimation results follow in section 5 . Section 6 reports the conclusions.

\section{Tariff regulation of the Italian water distribution sector}

The Italian water industry is composed of approximately 6,000 companies and is highly fragmented. For instance, there are water companies serving less than 5,000 customers and companies serving more than 300,000 customers. Some water companies operate at a provincial level, whereas others operate at a municipal level ${ }^{4}$. These companies, mostly public, are characterized by two main activities: production and distribution of water. Production involves the operation of facilities such as wells, pumps, storage facilities and purification plants.

Generally, the concession for the service is assigned directly from the local policy maker (provinces or municipalities) to publicly-owned firms, without a tendering process $^{5}$. Therefore, the water companies operate as legal local monopolists. Moreover, the tariffs of these water distribution companies are regulated at the local level. There are few cases of private companies in this sector.

\footnotetext{
4 In Italy there are 103 provinces, and each province consists of a number of municipalities.

5 Law no. 448/2001 ("Legge Finanziaria") has recently introduced compulsory competitive tendering for local public services. Law no. 448/2001 also defines the so-called "safeguard period," so competitive tendering will be actually operational only in few years.
} 
The rationale for the regulatory reform of 1994 introduced by the central government was the necessity to curb local balance deficits. For instance, the reform introduced the full cost pricing principle, so revenues have to cover all costs. Moreover, as already pointed out, with the introduction of this reform, the central government wanted to promote cost efficiency in this sector. For this reason, the reform introduced a regulation of the tariff at the national level based on a yardstick approach. In practice, each firm defines its own tariff composed of a fixed charge and a variable component and submits this tariff to the regulation authority for approval. The tariff is approved only if the level of the variable component does not exceed a range of approximately $30 \%$ with respect to the benchmarking value obtained using the estimation results of a variable cost function.

To correct the yardstick for the heterogeneity of the production process of water companies, the regulator uses the estimation results of a multivariate variable cost function. This cost function includes some observable output characteristics as explanatory variables. Thus, this model allows cost differences due to the heterogeneity of output to be corrected.

The parametric variable cost function for water distribution (also called "Metodo Tariffario Normalizzato," MTN) that the Italian Regulation Authority proposes for calculating and evaluating the tariff is the following:

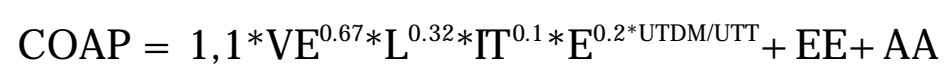

where:

COAP: = operating expenditure (millions lire/year)

$\mathrm{VE}=$ volume of water delivered (thousand $\mathrm{m}^{3} /$ year)

$\mathrm{L}=$ length of distribution network $(\mathrm{km})$

Utdm = measured volume of water delivered to householders

$\mathrm{UtT}=$ total users (sum of householders and non householders)

$\mathrm{EE}=$ expenditure for electricity (millions lire/year) 
$\mathrm{IT}$ = average pumping head

$A A=$ expenditure for water bought (millions lire/year)

The parameters of this mathematical expression have been obtained by estimating a variable cost function for a sample of 20 companies for the year 1991. The model specification employed by the Regulation Authority reflects the model estimated by Steward (1993) for a sample of UK water companies. 6

of course, a change in some coefficients of expression (1) could significantly change the values of predicted variable costs and, therefore, the results of the tariff calculation and evaluation process.

In the next section, we present the estimation results of a variable cost model, which, in comparison to the model (1) utilized by the regulation authority, includes more explanatory variables and has been estimated using panel data for a larger number of companies.

\section{Specification of a Variable Cost Function}

The costs of operating a water distribution system are the costs of building and maintaining the water system (distribution pipes, wells and springs), and of measuring and billing water. The water distributed by the companies comes from wells, springs and rivers or lakes. The main factors these costs may depend upon are:

(a) the total number of customers served;

(b) the type of consumer;

(c) the size and the morphology of the distribution area;

(d) the total water sold;

6 Steward (1993) estimated a variable cost function for a sample of water companies from the United Kingdom using a Cobb-Douglas functional form. As explanatory variables Steward considered: volume of water delivered, length of the network, share of water delivered to nondomestic consumers and the load factor. 
(e) the system of water collection (from springs, from wells, from rivers or from lakes);

(f) the length of distribution pipes and

(g) the input prices.

The most recent studies on the estimation of a cost function for the water industry distinguish the output scale effect from the network scale effect. For instance, Kim (1987), Kim and Clarc (1988), Fabbri and Fraquelli (2000) and Mizutani and Urakami (2001) examine the existence of economies of scale based on cost model specifications which include as explanatory variables some network characteristics variables. ${ }^{7}$ The inclusion in the cost model specification of a network variable, such as the length of the pipe, is very important for the analysis of the cost structure of this sector. For instance, even if the size of the output of two water distribution companies is the same, the cost level could be different because of different network size.

For the specification of the cost model, we have considered a water distribution company with three inputs, labor $(L)$, capital $(K)$ and energy $(E)$, which distribute a single output $\mathrm{Q}$ to a number of customers $\mathrm{CU}$ on a water system of size $\mathrm{N}$, which can be defined, for instance, by the length of the water system. The number of customers and the network size can be considered network characteristic variables.

If it is assumed that firms are not in static equilibrium with respect to one factor of production, capital stock, and that the firm minimizes variable cost, a cost function can be written as:

$$
C V=C(Q, P l, K, N, C U, L O, D T, T)
$$

7 The paper by Fabbri and Fraquelli (2000) is the most recent analysis on the cost structure of a sample of Italian water distribution companies. These authors estimate a translog total cost function using a cross-section of 173 water companies. Therefore, in contrast with our study, Fabbri and Fraquelli (2000) use cross-section data and assume that the water companies are in a long run equilibrium. In the model specification, they consider the following explanatory variables: price of labour, energy and materials, volume of water delivered, number of consumers, proxy of population density, price of water bought and treatment costs. 
where CV represents variable cost and Q is the output represented by the total cubic meters of water distributed, $\mathrm{PI}$ is the price of labor. ${ }^{8}$ The size of the water system is measured by the length of the pipes $(\mathrm{N})$, and the extent of the water system is measured by the number of customers (CU). LO is the percentage of water loss in the distribution pipes of the companies and is calculated as the ratio between the amount of water pumped into the pipes and the amount of water consumed by the customers. $\mathrm{K}$ is a proxy for the capital stock, which in this study is defined as the number of water wells employed by a company. Of course, we recognize that this proxy variable for the capital stock may not represent the actual amount of capital stock. Unfortunately no data on the balance sheet are available which would allow the calculation of the capital stock using the perpetual inventory method. DT is a dummy variable bearing value 1 if the firm distributes water that has to be treated chemically before distribution and 0 value otherwise. The treatment is necessary in a situation when, from a medical point of view, the quality of the water does not reach a predefined standard and, therefore, is not drinking water. $T$ is a time variable, which captures the shift in technology representing change in technical efficiency.

The properties of cost function (1) are that it is concave and linearly homogeneous in input prices, non-decreasing in input prices and output, and non-increasing with respect to capital stock. 9

Estimation of cost function (1) requires the specification of a functional form. Generally, the translog cost function offers an appropriate functional form for answering questions about economies of scale and density. However, as pointed out by Guyomard and Vermersch (1989) and by Filippini (1996), by estimating a translog variable cost function with a high number of explanatory variables a multicollinearity problem can arise. To determine whether multicollinearity between output and capital stock is causing a problem, we follow J udge et al. (1988) and Greene (1993) and examine the condition number of the

8 Unfortunately data on fuel prices are not available. However, according to some managers, the fuel price is more or less the same for all water companies. Therefore, the effect of this input price on cost is considered in the constant. 
explanatory variables. As expected, we found high values of the condition number mostly for the interaction variables of the translog functional form that include output, capital and the number of customers. For this reason we decided to employ a Cobb-Douglas functional form, which, in comparison to the translog form, reduces substantially the number of explanatory variables in the cost model. The major limit of this functional form is that the value of the economies of scale is constant.

The Cobb-Douglas form of (2) is

$$
\begin{aligned}
\ln (C V)= & \alpha_{0}+\alpha_{Q} \ln Q+\alpha_{N} \ln N+\alpha_{C U} \ln C U+\alpha_{P L} \ln P L+\alpha_{L O} \ln L O \\
& +\alpha_{K} \ln K+\alpha_{D T} D T+\alpha_{T} T+\varepsilon_{i t}
\end{aligned}
$$

\section{Data}

The models are estimated for panel data of publicly-owned water distribution companies serving Italian municipalities and provinces.

Our study is based principally on a database managed by CISPEL (the National Association of Local Public Service Firms), which collects financial and production data yearly for a sample of 50 water distribution firms. Additional technical and economic information was taken from a database on this sector built up by NOMISMA and by using a questionnaire sent to firms.

After this information was collected and data sets merged, the data consists of a sample of 32 water distribution firms for which all required data are available. For the estimation, panel data for five years, 1991, 1992, 1993, 1994 and 1995, have been used. The required data include the total cubic meters of water distributed per year, the total $\mathrm{km}$ of the water distribution system, the average price of labor, the average loss of water in the distribution and the technology adopted in the water system.

Total yearly variable cost is equated to the sum of direct $\operatorname{costs}^{10}$ and labor costs. Average yearly wage rates are estimated as the labor expenditure divided by the number of employees.

In Table 1 we present some statistics concerning the variables considered

${ }^{9}$ See Cornes (1992), p. 106. 
in model (2).

Table 1. Descriptive statistics

\begin{tabular}{|c|c|c|c|c|}
\hline Variables & Unit of measurement & $\begin{array}{c}\text { 1.Quartile } \\
\text { (small) }\end{array}$ & $\begin{array}{l}\text { Median } \\
\text { (medium) }\end{array}$ & $\begin{array}{l}\text { 3.Q uartile } \\
\text { (large) }\end{array}$ \\
\hline Variable cost & Italian Millions $\mathrm{f}$. & 1,820 & 4,398 & 6,748 \\
\hline Labor price & $\begin{array}{l}\text { Italian } f \text { for } \\
\text { worker unit }\end{array}$ & $58,638,000$ & $63,606,000$ & $69,690,000$ \\
\hline Capital stock & & 3 & 12 & 25 \\
\hline Output & $\begin{array}{c}\text { Cubic meters of } \\
\text { water }\end{array}$ & $3,811,000$ & $6,772,000$ & $14,217,000$ \\
\hline Water system & Linear Km & 146 & 228.5 & 748 \\
\hline Water loss & & 0.098 & 0.172 & 0.258 \\
\hline Number of customers & & 4,828 & 14,004 & 28,374 \\
\hline & & \multicolumn{2}{|c|}{ No. of 0} & No. of 1 \\
\hline $\begin{array}{l}\text { Dummy for treatment of } \\
\text { water }\end{array}$ & $\begin{array}{c}\text { Takes the value } 0 \text { or } \\
1\end{array}$ & \multicolumn{2}{|l|}{29} & 3 \\
\hline
\end{tabular}

\section{The variable cost function results}

With regard to choice of econometric technique, it should be noted that in the econometric literature we can find various types of models focusing on crosssectional variation, i.e., heterogeneity across units. ${ }^{11}$ The three most widely used approaches are: the OLS model, the least squares dummy variable (LSDV) model, and the error components model (EC). The fact that the variable cost function (2) includes explanatory variables that remain constant over time excludes the possibility to estimate equation (3) by LSDV. Therefore, equation (3) has been estimated using the OLS and the EC models.

The estimated coefficients and their associated standard errors of the cost model (3) are presented in Table 2. The estimated functions are well behaved.

10 Direct costs are costs of purchased goods and services. 
Most of the parameter estimates are statistically significant and carry the expected sign.

To test whether individual effects are present we ran a Lagrange Multiplier test for the random effects model. The result of this test favors the random effects model over the OLS model. However, the estimated coefficients, apart from some exceptions, do not vary very much between the two specifications.

Since total cost and the regressors are in logarithms, the coefficients are interpretable as cost elasticities. Most of these coefficients have the expected signs and are significant. The output elasticity is positive and implies that an increase in the production will increase variable cost. A $1 \%$ increase in the quantity of distributed water will increase the variable cost by approximately $0.6 \%$.

The cost elasticities with respect to the size of the water distribution system, to the number of customers and to the loss of water are positive and imply that an increase in these variables will increase variable cost.

The cost elasticity with respect to the output found in this paper is very similar to the one employed in the parametric cost function (1), whereas the values of the cost elasticity with respect to the network length are different.

Table 2. Variable cost parameter estimates (standard errors in parentheses)

\begin{tabular}{ccc}
\hline \multirow{2}{*}{ Coefficient } & OLS & Random-effects (GLS) \\
\hline Constant & $7.071^{* * *}$ & $8.900^{* * *}$ \\
& $(2.274)$ & $(1.917)$ \\
?Q & $0.689 * * *$ & $0.603^{* * *}$ \\
& $(0.045)$ & $(0.091)$ \\
?N & $0.191^{* * *}$ & $0.275^{* * *}$ \\
& $(0.052)$ & $(0.097)$ \\
CU & $0.176^{* * *}$ & $0.185^{* * *}$ \\
& $(0.049)$ & $(0.089)$
\end{tabular}

11 See Greene (1993) for a presentation of the panel econometric approaches. 


$\begin{array}{ccc}\text { LO } & 0.010^{* *} & 0.008^{* *} \\ & (0.006) & (0.010) \\ \text { ?PL } & 0.327 * * * & 0.237^{* *} \\ & (0.132) & (0.107) \\ \text { K } & -0.005 & -0.007 \\ & (0.006) & (0.013) \\ \text { ?DT } & 0.472 * * * & 0.411^{* *} \\ \text { ?T } & (0.095) & (0.217) \\ & -0.002 & -0.031 \\ \text { Adjusted R } & (0.016) & (0.007) \\ & & \end{array}$

The labor cost share is positive, implying that the cost function grows monotonically in this input price.

A well-defined variable cost function should be non-increasing with respect to capital stock. The coefficient of capital stock is negative but not significant. This result indicates, as normally expected in cost theory, that a marginal increase in the capital stock does not cause an increase in variable costs. However, this result has to be interpreted carefully because of the kind of proxy variable used in the model for the capital stock.

As expected, the coefficient of the dummy variable DT is significant in both models. This result shows that companies that have to treat part of the water chemically (transformation into drinking water) show higher costs than the other companies.

The inclusion in the cost function of the number of customers and the size of the service territory allows for the distinction of economies of output density, economies of customer density and economies of scale. Following Caves et al. (1981), Roberts (1986) and Filippini (1996, 1998), we define economies of output density (EOD) as the proportional increase in variable costs brought about by a proportional increase in output, holding all input prices, the number of customers and the size of the water system fixed. This is equivalent to 


$$
E O D_{V C}=\frac{1-\frac{\partial \ln V C}{\partial \ln K}}{\frac{\partial \ln V C}{\partial \ln Q}}
$$

We will talk of economies of output density if EOD is greater than 1, and accordingly, diseconomies of output density if EOD is below 1 . In the case of EOD $=1$ no economies or diseconomies of output density exist. Economies of output density exist if the average costs of a water distribution company decrease as the volume of water sold to a fixed number of customers in a service territory of a given size increases.

Economies of customer density (ECD) are defined as the proportional increase in variable costs brought about by a proportional increase in output and the number of customers, holding all input prices and the size of the water distribution system fixed. Economies of customer density (ECD) can thus be defined as

$$
E C D_{V C}=\frac{1-\frac{\partial \ln V C}{\partial \ln K}}{\frac{\partial \ln V C}{\partial \ln Q}+\frac{\partial \ln V C}{\partial \ln C U}}
$$

We will talk of economies of customer density if ECD is greater than 1, and accordingly, diseconomies of scale if ECD is below 1 . In the case of ECD $=1$ no economies or diseconomies of customer density exist. This measure is relevant for analyzing the cost of distributing more water to a fixed service territory as it becomes more densely populated.

Economies of scale (ES) are defined as the proportional increase in variable costs brought about by a proportional increase in output, the number of customers and the size of the water system, holding all input prices fixed. Economies of scale (ES) can thus be defined as 


$$
E S_{V C}=\frac{1-\frac{\partial \ln V C}{\partial \ln K}}{\frac{\partial \ln V C}{\partial \ln Q}+\frac{\partial \ln V C}{\partial \ln C U}+\frac{\partial \ln V C}{\partial \ln N}}
$$

We will talk of economies of scale if ES is greater than 1, and accordingly, diseconomies of scale if ES is below 1 . In the case of ES $=1$ no economies or diseconomies of scale exist. This measure is relevant for analyzing the impact on cost of merging two adjacent water distribution companies.

Table 3 presents the estimates of economies of output density, customer density and economies of scale calculated using the estimation results from model GLS. We note that the indicators for economies of output density and customer density are greater than 1, whereas the indicator for economies of scale is lower than 1. This means that the majority of the Italian water distribution companies operate at an inappropriate low-density level, but, in terms of size, they experience a weak situation of diseconomies of scale.

Thus, water distribution companies that increase output, the number of customers, and the length of the pipes proportionally will not experience economies of scale.

Table 3. Economies of scale and density

\begin{tabular}{|c|c|}
\hline EOD & 1.46 \\
\hline ECD & 1.16 \\
\hline ES & 0.95 \\
\hline
\end{tabular}


The estimated indicators of economies of output and customer density can clarify the efficiency of side-by-side competition at all points of a given service territory versus monopolistic provision of water. The finding shows that the cost of serving a market of size y over a municipal territory with one water company is lower than the cost of serving the same market with $n$ competitive companies, which install parallel water distribution pipes everywhere. Moreover, the merger between two companies with adjacent water distribution systems will, because of diseconomies of scale, not allow a decrease in the average distribution costs. The results in terms of economies of density and scale confirm the values obtained by Fabbri and Fraquelli (2000), who estimated a total cost function for a crosssection of 173 Italian water distribution companies.

Finally, the estimation results presented in Table 2 could be used to predict average costs for water distribution companies with different area characteristics and, therefore, perform a yardstick price regulation as suggested by Shleifer (1985).

For illustrative purposes we utilized the econometric results reported in Table 2 to estimate the average distribution costs for water utilities with different network sizes. Table 4 shows the results of this simple simulation exercise.

Table 4 Predictions of the average cost for a medium-sized water distribution in Lire per cubic meter, 1995 prices

\begin{tabular}{|c|c|c|}
\hline & $\begin{array}{c}\text { Medium size company } \\
\text { without chemical treatment } \\
\text { (DT }=0 \text { ) } \\
\text { (output: } \sim 7,000,000 \mathrm{~m} 3 \\
\text { and } \\
\text { customers: } \sim 14,000 \text { ) }\end{array}$ & $\begin{array}{c}\text { Medium size company } \\
\text { without chemical treatment } \\
\text { (DT }=1 \text { ) } \\
\text { (output: } \sim 7,000,000 \mathrm{~m} 3 \\
\text { and } \\
\text { customers: } \sim 14,000)\end{array}$ \\
\hline $\begin{array}{l}\text { Length of the network } \\
126 \mathrm{~km}\end{array}$ & 366 & 550 \\
\hline $\begin{array}{l}\text { Length of the network } \\
248 \mathrm{~km}\end{array}$ & 412 & 622 \\
\hline $\begin{array}{l}\text { Length of the network } \\
748 \mathrm{~km}\end{array}$ & 569 & 857 \\
\hline
\end{tabular}


The results reported in Table 2 confirm that with the increase in the size of the network, the average costs increase (scale effect).

\section{Conclusions}

In the water distribution sector, the Italian regulator has adopted an incentive regulation approach based on the idea of yardstick regulation suggested by Shleifer (1985). The benchmarking procedure contained in this regulation approach consists of the comparison of the actual variable costs of the companies against a benchmark performance calculated using the econometric estimation results of a variable cost function estimated for a cross-section of a sample of Italian water companies.

The purpose of this study has been to estimate a variable cost function using panel data for a sample of 32 Italian water companies, in order to analyze the economies of scale and density and to compare estimation results with those employed at present by the Italian Regulation Authority.

The two most important improvements of our model in comparison to the one used by the Regulation Authority are: the use of panel data and the inclusion in the cost model of some new variables such as the number of customers, the price of labor and the percentage of water loss in the distribution pipes.

The conclusions of our study are the following:

1. There are economies of output and customer density. These findings indicate that there would be efficiency losses if individual customers were served by more than one water distribution company.

2. There is no evidence that larger service areas result in any economies in water distribution. This means that a merger between two companies with adjacent service areas does not substantially decrease average cost.

3. The coefficient of chemical treatment is significant. This confirms the relevance of geographical and morphological variables in water cost estimation. In this perspective, the inclusion of geographical and morphological variables in the variable cost model specification seems very important in order to obtain an effective tariff regulation. 
4. The cost elasticity with respect to the output found in this paper is similar to the one employed by the Italian Regulation Authority. However, the cost elasticity with respect to the network size found in this study is different from the one employed by the Italian Regulation Authority. These results confirm that caution should be exercised in using the estimation results of a variable cost function in the tariff regulation process.. In fact, predictions on average costs, and, therefore, yardstick regulation, should be based on a carefully and robust specified cost model. 


\section{References}

Baltagi, Badi H. and Griffin, James M. (1984), Short and Long Run Effects in Pooled Models, International Economic Review, 25 (3), 631-645.

Burns, P., and Weyman-J ones, T.G., 1996, Cost Functions and Cost Efficiency in the Electricity Distribution: a Stochastic Frontier Approach, Bulletin of Economic Research, 48, 4264.

Callan, S.J., 1991, The Sensitivity of Productivity Growth Measures to Alternative Structural and Behavioral Assumptions: An Application to Electric Utilities 1951-1984, Journal of Business \& Economics Statistics, 9, 207-213.

Caves, W.C., Christensen, L.R. and Swanson, J.A., 1981, Productivity Growth, scale economies, and capacity utilization in U.S. railroads, 1955-74, American Economic Review, 71, 994-1002.

Filippini, M., 1996, Economies of Scale and Utilization in the Swiss Electric Power Distribution Industry. Applied Economics, 28, 543-550.

Filippini, M., and Maggi, R., 1993, Efficiency and Regulation in the case of the Swiss Private Railways, J ournal of Regulatory Economics, 5, 199-216.

Filippini, M., 1996, Economies of Scale and Utilization in the Swiss Electric Power Distribution Industry, Applied Economics, 28, 543-550.

Filippini, M., 1997, Elements of the Swiss Market for Electricity, Physica, Berlin.

Filippini, M., 1998, Are Municipal Electricity Distribution Utilities Natural Monopolies?, Annals of Public and Cooperative Economics, 69, 157-74.

Friedlaender, A.F., and Wang Chiang, J.S.E., 1983, Productivity Growth in the Regulated Trucking Industry, Research in Transportation and Economics, 1, 149-184.

Hayashi, P.M., Goo, J.Y.-J., and Chamberlain, W.C., 1997, Vertical Economies: The Case of the U.S. Electric Utility Industry, 1983-87, Southern Economic J ournal, 63, 710-725.

Kittelsen, S.A.C., 1995, Regulation Electricity Distribution Utilities with Yardstick Competition Based on DEA, New England Conference on Efficiency and Productivity, University of New England, NSW, Australia, 23-24 November 1995.

Laffont, J.J., and Tirole, J., 1993, A Theory of Incentives in Procurement and Regulation, MIT Press, Cambridge, Massachusetts.

Nelson, R.A., and Primeaux, W.J. J r., 1988, The Effects of Competition on Transmission and Distribution Costs in the Municipal Electric Industry, Land Economics, 64, 338-346.

Neuberg, L.G., 1977, Two issues in the municipal ownership of electric power distribution systems, Bell J ournal of Economics, 8, 302-322.

Pollitt, M.G., 1995, Ownership and Performance in Electric Utilities: The Inter-national Evidence on Privatization and Efficiency, Oxford. 
Roberts, M.J., 1986, Economies of Density and Size in the Transmission and Distribution of Electric Power, Land Economics, 62, 378-387.

Salvanes, K.G., and Tjøtta, S.,1994, Productivity Differences in Multiple Output Industries: An Empirical Application to Electricity Distribution, The J ournal of Productivity Analysis, 5, 23-43.

Shleifer, A., 1985, A Theory of Yardstick Competition, Rand J ournal of Economics, 16, 319-327. Swiss Federal Office of Energy, 1998, Elektrizitätsmarktgesetz (EMG), Entwurf vom 18. February 1998, Bern.

Swiss Federal Office of Energy, various years, Finanzstatistik, Bern.

Weyman-J ones, T., 1995, Problems of Yardstick Regulation in Electricity Distribution, in: Bishop, M., Kay, J., and Mayer, C. (eds.), The Regulatory Challenge, Oxford University Press, Oxford. 


\title{
QUADERNI DELLA FACOLTÀ
}

\author{
I quaderni sono richiedibili (nell'edizione a stampa) alla Biblioteca universitaria di Lugano \\ via Ospedale 13 CH 6900 Lugano \\ tel.+41919124675; fax+41919124647; e-mail: biblioteca@lu.unisi.ch \\ La versione elettronica (file PDF) è disponibile all'URL: \\ http://www.lu.unisi.ch/biblioteca/Pubblicazioni/f_pubblicazioni.htm
}

The working papers (printed version) may be obtained by contacting the Biblioteca universitaria di Lugano via Ospedale 13 CH 6900 Lugano

tel.+41919124675; fax+41919124647; e-mail: biblioteca@lu.unisi.ch

The electronic version (PDF files) is available at URL:

http://www.lu.unisi.ch/biblioteca/Pubblicazioni/f_pubblicazioni.htm

Quaderno n. 98-01

P. Balestra, Efficient (and parsimonious) estimation of structural dynamic error component models

Quaderno n. 99-01

M. Filippini, Cost and scale efficiency in the nursing home sector : evidence from Switzerland

Quaderno n. 99-02

L. Bernardi, I sistemi tributari di oggi : da dove vengono e dove vanno

Quaderno n. 99-03

L.L. Pasinetti, Economic theory and technical progress

Quaderno n. 99-04

G. Barone-Adesi, K. Giannopoulos, L. Vosper, VaR without correlations for portfolios of derivative securities

Quaderno n. 99-05

G. Barone-Adesi, Y. Kim, Incomplete information and the closed-end fund discount

Quaderno n. 99-06

G. Barone-Adesi, W. Allegretto, E. Dinenis, G. Sorwar, Valuation of derivatives based on CKLS interest rate models

Quaderno n. 99-07

M. Filippini, R. Maggi, J. Mägerle, Skalenerträge und optimale Betriebsgrösse bei den schweizerische Privatbahnen

Quaderno n. 99-08

E. Ronchetti, F. Trojani, Robust inference with GMM estimators 
Quaderno n. 99-09

G.P. Torricelli, I cambiamenti strutturali dello sviluppo urbano e regionale in Svizzera e nel Ticino sulla base dei dati dei censimenti federali delle aziende 1985, 1991 e 1995

Quaderno n. 00-01

E. Barone, G. Barone-Adesi, R. Masera, Requisiti patrimoniali, adeguatezza del capitale e gestione del rischio

Quaderno n. 00-02

G. Barone-Adesi, Does volatility pay?

Quaderno n. 00-03

G. Barone-Adesi, Y. Kim, Incomplete information and the closed-end fund discount

Quaderno n. 00-04

R. Ineichen, Dadi, astragali e gli inizi del calcolo delle probabilità

Quaderno n. 00-05

W. Allegretto, G. Barone-Adesi, E. Dinenis, Y. Lin, G. Sorwar, A new approach to check the free boundary of single factor interest rate put option

Quaderno n. 00-06

G.D.Marangoni, The Leontief Model and Economic Theory

Quaderno n. 00-07

B. Antonioli, R, Fazioli, M. Filippini, Il servizio di igiene urbana italiano tra concorrenza e monopolio

Quaderno n. 00-08

L. Crivelli, M. Filippini, D. Lunati. Dimensione ottima degli ospedali in uno Stato federale

Quaderno n. 00-09

L. Buchli, M. Filippini, Estimating the benefits of low flow alleviation in rivers: the case of the Ticino River

Quaderno n. 00-10

L. Bernardi, Fiscalità pubblica centralizzata e federale: aspetti generali e il caso italiano attuale

Quaderno n. 00-11

M. Alderighi, R. Maggi, Adoption and use of new information technology

Quaderno n. 00-12

F. Rossera, The use of log-linear models in transport economics: the problem of commuters' choice of mode

Quaderno n. 01-01

M. Filippini, P. Prioni, The influence of ownership on the cost of bus service provision in Switzerland. An empirical illustration 
Quaderno n. 01-02

B. Antonioli, M. Filippini, Optimal size in the waste collection sector

Quaderno n. 01-03

B. Schmitt, La double charge du service de la dette extérieure

Quaderno n. 01-04

L. Crivelli, M. Filippini, D. Lunati, Regulation, ownership and efficiency in the Swiss nursing home industry

Quaderno n. 01-05

S. Banfi, L. Buchli, M. Filippini, Il valore ricreativo del fiume Ticino per i pescatori

Quaderno n. 01-06

L. Crivelli, M. Filippini, D. Lunati, Effizienz der Pflegeheime in der Schweiz

Quaderno n. 02-01

B. Antonioli, M. Filippini, The use of a variable cost function in the regulation of the Italian water industry 